\title{
Management of jealousy in couples
}

\author{
Michael Crowe
}

Jealousy has traditionally been treated by offering medication, support, or various forms of individual psychotherapy or counselling. However, jealousy is usually a condition which has a profound effect on the sexual partner of the jealous person, and they may actually suffer more from the condition than the person him/herself. While accepting that medication and other individual approaches have their place in the management of jealousy, there seem to be several advantages in seeing the problem from the standpoint of the couple relationship. Firstly, couple therapy reduces the almost inevitable labelling of the jealous person as a psychiatric case. Secondly, one might argue a priori that any changes which take place as a result of two people changing their behaviour are likely to be more stable and long-lasting than if just one person changes. There is another consideration, namely that, since the relationship is bound to be affected by the jealousy, it will need attention regardless of the means used to treat the jealousy itself.

\section{Nature of jealousy}

Jealousy has been a topic of fascination for playwrights and poets throughout the ages, from Euripides and Shakespeare onwards (Shepherd, 1961). In its clinical presentation it may be divided into two main forms, normal jealousy and morbid jealousy. In normal jealousy there is a publiclyrecognised outside relationship occurring and the uninvolved partner is upset by it and feels angry, resentful, and bitter about it. In morbid jealousy, on the other hand, there is either no public admission of the affair that the person suspects to be occurring, or there is an excessive reaction to an admitted affair on the part of the jealous person. Morbid jealousy can itself be subdivided into those cases where there is an accompanying psychosis (delusional jealousy) and those where there is no such process occurring. These subdivisions of jealousy are similar but not identical to those used by de Silva \& Marks (1994).

Normal jealousy is probably more common than is generally realised (White \& Mullen, 1989; Tarrier et al, 1990). Indeed, in a community study, Mullen \& Martin (1994) found that no respondent had been totally free of jealousy during his life, that 164 out of 351 subjects had experienced higher levels of jealousy, and $66(19 \%)$ had significantly high (i.e. equivalent to clinical) concerns with jealousy.

From a clinical or diagnostic point of view, jealous ideas are often quite difficult to disprove. Unless they are so bizarre as to be obviously delusional, it is frequently possible to persuade oneself as a therapist that the affair may indeed be taking place as the jealous partner believes, and in some cases a patient with ' morbid' jealousy has been shown later to have been justified in his suspicions.

It is probable that most cases of jealousy within couples do not come to clinical attention. It is not clear from Mullen \& Martin's (1994) work how many of the jealous individuals in the community consulted their doctors about the problem, but it seems likely that only a very small proportion did so. However, jealousy forms a small but significant part of most general psychiatrists' case-load, and is the occasion of domestic violence in some cases.

The cases seen in our clinic are mostly those who are morbidly jealous without being psychotic. There is a very characteristic feel to their interaction which is difficult to describe but which can be easily sensed by the couple therapist. One of the most constant features is the difficulty of saying anything without offending one or the other partner. For example, in one case the husband was convinced that his wife was seeing another man, and accused her of having an affair and lying about it. She, on the other hand, denied the affair and accused the husband of being psychotically jealous. The therapist could not use the word 'jealousy' without

Dr Michael Crowe, FRCPsych, is a consultant psychiatrist at the Bethlem \& Maudsley NHS Trust, The Maudsley Hospital, Denmark Hill, London SE5 8AZ. He has run clinics for sexual and relationship problems for 20 years. He also chairs the Behavioural and Cognitive Psychotherapy Group of the Royal College Psychotherapy Section. 
offending the husband, or the word 'affair' without the wife complaining that the therapist was on her husband's side. This sense of treading on eggshells is very common in treating such couples.

Apart from this, the jealous behaviour in the session is very similar to the classical descriptions in the literature. The jealous partner may interrogate the other about fine details of his daily movements, repeating questions and trying to trick him into an admission. They may also examine diaries, handbags, clothing, and so on, for evidence of an illicit relationship, and may even follow the partner to work or hire detectives to do so. In some cases violence may ensue, especially when alcohol is being consumed.

The non-jealous partner, on the other hand, is usually shocked at the accusations, and will use various means to protest his innocence, including offering to be hypnotised or to take a truth drug. He will also use mainly logical arguments to persuade the other that there is no affair going on, and will usually assume that the jealous partner is ill or mad to act in this way.

However, the above description of the couple's behaviour assumes that the jealous partner has initiated the problem. A systemic viewpoint does

\begin{tabular}{|c|c|}
\hline Jealous person & Partner \\
\hline Dependent & $\begin{array}{l}\text { Outgoing and } \\
\text { independent }\end{array}$ \\
\hline $\begin{array}{l}\text { Desires exclusive } \\
\text { relationship }\end{array}$ & $\begin{array}{l}\text { Less overtly } \\
\text { committed }\end{array}$ \\
\hline Insecure & $\begin{array}{l}\text { May feel } \\
\text { 'unattractive' }\end{array}$ \\
\hline Interrogates & $\begin{array}{l}\text { Denies but restricts } \\
\text { activities }\end{array}$ \\
\hline 'Detective work' & Resentment \\
\hline Violence & $\begin{array}{l}\text { Secondary } \\
\text { depression }\end{array}$ \\
\hline $\begin{array}{l}\text { Psychiatric illness } \\
\text { (e.g. paranoid } \\
\text { ideas, depression } \\
\text { or alcoholism) }\end{array}$ & $\begin{array}{l}\text { Personality traits } \\
\text { (e.g. flirtatious or } \\
\text { provocative) }\end{array}$ \\
\hline
\end{tabular}

not assume that either partner is entirely responsible for the situation, but prefers to see the problem as arising from a circular chain of causation to which both partners may be contributing. So, for example, the non-jealous partner may be doing something, albeit unintentionally and even unconsciously, to exacerbate the situation. They may be less committed than their partner to a oneto-one relationship, and may seem, in the process of daily life, to be paying more attention to friends or acquaintances than to the partner. They may seem to believe others in preference to the jealous partner, and to take others' advice more seriously. They may even seem to provoke a jealous reaction, for example by breaking a silence by saying "I expect you are having jealous thoughts".

The relationship itself may be contributing to the problem, with misunderstandings and partial communications giving rise to suspicions and resentments. In other couples the jealousy may be counteracting an existing imbalance in the relationship, with the non-jealous partner 'getting away' with too much dominance and the jealousy providing the jealous partner with a means of attracting his/her attention. In other cases the relationship may be rather stuck in repetitive routine, and the jealousy may provide a kind of variety (albeit painful) in the couple's lives.

\section{Couple therapy}

How, then, may we as couple therapists tackle the problem of jealousy within the therapeutic setting? Firstly it would be useful to outline the behaviouralsystems approach to couple therapy (Crowe \& Ridley, 1990), which forms the basis of our approach to the management of jealousy and many other relationship problems. This is a practical and eclectic form of therapy which concentrates on problem-solving and planning for the immediate future rather than seeking the causes of behaviour in the more distant past. There are essentially five levels (with two alternative approaches) in the therapeutic repertoire, which are used in response to different presenting problems in the couple, and the therapist can move from one to the other at different stages of the same session.

The hierarchy of alternate levels of intervention (ALI) is an easy way for the therapist to decide which of the various types of intervention to use for the couple in response to the type of problem or interaction which they are presenting in the session (see Fig. 1). The interventions at the different levels are described in the next section. 


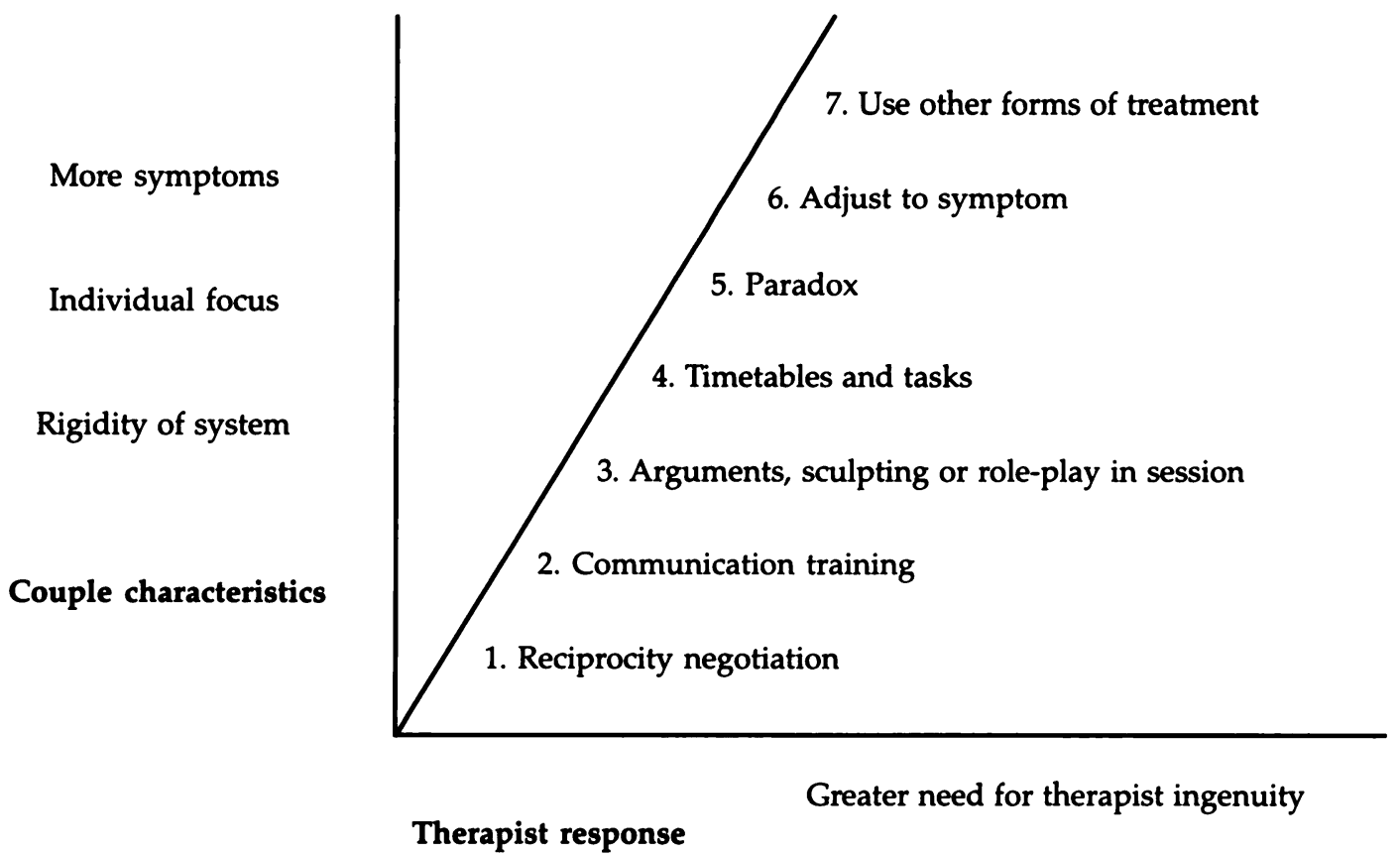

Less reliance on couple's stated goals

\section{Fig. 1. The ALI hierarchy: general principles (from Crowe \& Ridley, 1990)}

\section{Alternative levels of intervention}

(1) Reciprocity negotiation. The couple is encouraged to take specific issues and negotiate more positive ways of solving the problems - simplifying requests, turning mutual complaints into wishes, turning wishes into tasks, and agreeing on plans for carrying out these tasks during the following week. For example, in one particular couple the jealous wife was upset because the husband did not telephone her when he was delayed at work. Clearly she thought that he might be seeing his 'lover', but when a simple arrangement was made for him to phone after a set time in the evening she was greatly reassured and became significantly less disturbed by his late evening work. In return she agreed to speak with him in a friendly way when he first got in from work.

(2) Communication training. The couple are asked to communicate in a simple, open and constructive way, speaking in brief sentences and acknowledging that they have heard what their partner has just said. They should also avoid 'mindreading' and should try to show empathy and understanding with the other's feelings. For example, a jealous man was describing his wife's 'flirtatious' behaviour with male strangers as being designed to provoke him and make him angry. The therapist asked him to use terms which did not assume that he could read her mind, and he was then able to see that perhaps he had jumped to conclusions about her intentions, and that she was simply being pleasant and disarming to avoid aggression from the strangers. She was then able to appreciate that her behaviour provoked him unintentionally, and began to be less overtly friendly to the others.

(3) In-session structural interventions. These include encouraging some couples who are reluctant to raise their voices, or where one partner is very unassertive, to have lively discussions or arguments in the session, and the therapist will encourage them both to argue their side of the case and not to 'give in for the sake of peace'. These interventions also include direct and reversed roleplay (in the latter, the partners put each other's point of view instead of their own), and 'sculpting', in which they wordlessly position themselves and each other to represent the current state of the relationship. In one couple the jealous husband was very assertive when he was talking about his wife's supposed affairs, but very unassertive on other issues such as her exclusive relationship with her mother, in which she organised all matters to do with their children without reference to him. He was able to stand out for more involvement, and 
became more active in looking after the children. His assertiveness was associated with a decrease in the jealous behaviour.

(4) Messages, tasks and timetables. These are usually given as homework exercises between sessions. The therapist comes back into the session after a consultation with the team, and gives them a formulation of the current state of their problem, together with some tasks to be carried out before the next session. The tasks may be for an enjoyable outing (but often with a systemic link such as to go out without telling a key member of the family where they are going), or for a 10-minute talk together each night, or for a planned argument with a time limit, or for many other joint or separate activities. Sometimes the task is to do something spontaneous at the weekend, or sometimes it may involve one partner doing a specific activity such as taking the children to the park.

Sometimes the tasks are timetabled. The timetabled tasks will usually be those activities which appear to be out of control, in the sense that one partner is disturbed by the frequency with which the other one wishes to carry them out. One obvious example of this sort of activity is sex (Crowe \& Ridley, 1986), and this is often the subject of a timetable. Another is jealous interrogation, and timetables can be a mainstay of the management of jealousy in couples. The essence of the timetable is that the activity is programmed to take place for a limited period, perhaps once a day, but that if the enthusiastic partner wants to do it at any other time the other partner has to say "Yes, but not until (e.g.) $8 \mathrm{pm}$ ". The timetable is a good intervention in that it allows the activity to be carried out legitimately (favouring the jealous partner) but limits its frequency and duration (favouring the other partner), and reduces any overt conflict about whether the activity should take place. Thus in one couple the timetable was for them to take an hour each evening for the jealous husband to interrogate his wife on her 'infidelity'. He kept this up for about two weeks, but then began to find that it was becoming harder to find subjects to raise and began to give her 'evenings off' with no interrogation, to her obvious relief.

(5) Paradox. This is a systemic intervention which is based on the concepts of Selvini Palazzoli et al (1978). If the couple is 'stuck' in a particular pattern of interaction which seems to be rigid in the systemic sense of the word, and if they seem to be impervious to attempts to alter their interaction by reciprocity negotiation, communication training, structural approaches or tasks and timetables, the time may be right to attempt a paradox.
The paradox should be prepared quite carefully, with good team discussion before it is presented, and is in no sense to be given in a tongue-in-cheek or sarcastic manner. The essence of this type of intervention is that it does not matter very much whether the couple carry out the paradoxical task as instructed, or do the opposite. The important thing is that it makes them think in a different way about their problems and gives them the choice whether to accept the 'crazy' ideas presented, or to 'resist' the therapist and in effect reduce the problem. Examples of typical paradoxical injunctions are: (a) prescribing the patient's symptom and the reciprocal behaviour of the non-symptomatic partner, 'because it is helpful to the relationship'; and (b) the 'therapist put-down', in which the therapist says that he/ she has been hopelessly overoptimistic in expecting the couple to solve their problem behaviour because the problem is obviously stabilising their relationship and they cannot manage without it. An example of paradox is given in the case history below.

(6) Adjust to the symptom. In some cases it is impossible to shift the system by any of the methods outlined above, and it becomes necessary to help the couple to 'live with' the problem. The interventions at this level may be rather similar to those used in the first two levels, but the difference is that they are not expected to alter the symptom (e.g. psychotic jealousy) but simply to help the couple to make the best of their relationship in spite of the continuing problem.

(7) Other forms of treatment. It should be mentioned that it is possible to combine the behavioural systems approach with other treatments such as drug therapy or behaviour therapy. It may well be necessary, in treating a jealous patient most effectively, to stop treating the couple altogether and use, for instance, antipsychotic medication for the problem (see Box 2).

\section{Case example}

This case is presented because the husband's jealousy was of an almost psychotic intensity, but after a series of 12 couple therapy sessions over 15 months it resolved without medication.

Roger had been married to Susan for 14 years (names and details have been changed). He was 44 and she was 39. It was her first marriage but his second, and his first marriage had broken up following accusations of infidelity that he had made 
Box 2. Different therapeutic approaches to jealousy

Individual psychotherapy: Dynamic Cognitive Eclectic

\section{Couple therapy:}

Reciprocity negotiation

Communication training

Reversed roles

Timetables

Paradoxical injunctions

Physical treatments:

Antidepressants

Phenothiazines

\section{Other approaches:}

Reduce alcohol intake

Separate the partners

against his former wife, and which he was now sure had been justified. There were no children in the present marriage, and Roger had had a vasectomy following the first marital break-up.

The reasons for referral were: (a) Roger's jealousy; (b) violent rows resulting from this; (c) his depression; and (d) Susan's distress. The problems had continued for about 12 months and had worsened following his taking sick leave from work. Susan herself had been made redundant from a valued job which she had held for 20 years, and was working as a part-time shop assistant. Roger was more worried than Susan about their financial security and the adverse consequences of his possibly being forced to take retirement.

The jealousy had begun a year before the referral, following the visit to their home of a window cleaner. Roger accused Susan of having an affair because she had looked at the window cleaner in a 'flirtatious' way. He also accused her of making an assignation with a salesman who had called at the house. She reassured him that there was no basis to his fears, but to no avail.

Susan did not respond passively to his accusations. At times she would vehemently deny that she had had affairs, while at other times she became quite violent and attacked Roger. When he had outbursts in the night, however, she would usually make tea for him in order to help him sleep.

In therapy we began by trying to reframe the problem as one of interaction, and worked simul- taneously on the marital problems and the jealousy. They were able to communicate surprisingly well on most topics, although the subject of infidelity caused expected misunderstandings. We did not need to work much at the lower levels (1 and 2, above) of the hierarchy. Instead we concentrated on ways of reducing the impact of the jealousy on the relationship.

At the end of the first session a timetable was suggested, which it was hoped would contain the problem without labelling Roger as a 'patient' or denying the validity of his and Susan's feelings. Each day they were to set aside an hour when they were to argue about the accusations, Roger making his points and Susan rejecting them. They were asked to cease discussion at the end of the hour, and as they felt that it would be impossible to do this in the house, they agreed to go for a walk together when the hour was over. If, however, the topic came up at any other than the appointed time, Susan was to say "we will discuss that at noon tomorrow".

The timetable was only partially successful, in that they had used the hour as planned each day, but Roger had been unable to restrain himself in the night and had raised the accusations, keeping Susan awake on at least half the nights between the first and second session. In the second session a 'reversed role-play' had been used (see de Silva, 1987), in which the therapist asked Susan to act as if she were jealous of Roger and accuse him of having affairs at his work. This made both partners laugh; however, the improvement was short-lived and in the fourth session the couple seemed to be back in their familiar pattern of repetitive arguments about affairs, with both partners wanting a more powerful intervention.

It was at this point that the team decided to use a paradox, using systemic ideas generated from the session in framing the message, and putting them across in a way that was at the same time palatable and challenging to the couple (see 5, above).

The basis for the paradox in this case was as follows. They had a childless marriage, but Susan was a motherly person who had herself recently been deprived of a role at work that involved looking after others. Roger had also been deprived of a rewarding job, although temporarily, and was feeling low. It was hypothesised that the jealousy provided Susan with a 'crying baby' to look after, while Roger gained a mother who would look after him in his distress and bring him drinks and comfort when he needed them.

The essence of a paradox is that the therapist prescribes the symptom of the 'patient' and the behaviour of the partner that goes with it, but for a reason which the couple have not identified and 
which might be seen by them as challenging or unacceptable. In this case the paradoxical injunction was that the couple should not change their interaction over the jealousy, Roger continuing to 'cry' over Susan's infidelity and Susan mothering him by reassuring, by providing drinks and by listening to his worries. They should continue doing this because ( to give the systemic reason) they needed to have an unequal relationship which prevented them fighting and arguing in other ways as equal opponents, and perhaps splitting up.

The couple's response to this paradox was interesting. Susan replied "I don't think I mother him all the time" and Roger said "So you think we would quarrel?". The message was repeated with variations in subsequent sessions, and gradually Susan became more dispirited, while Roger lost some of his depressive symptoms. He himself made a considerable effort to 'mother' Susan and to make her feel more cheerful. The therapy continued for a few more months, and gradually the jealousy reduced in frequency and intensity, from several times a day at the beginning of therapy to once in three weeks at the end. At the same time the couple's general relationship improved, becoming more peaceful and more equal.

\section{Discussion}

The use of the three types of intervention timetables, reversed role-play, and paradox - has the effect in each case of 'normalising' the jealousy, either by prescribing it at selected times (timetable), by asking the non-jealous partner to be jealous (roleplay) or by asking them to carry on with the jealousy without inhibition (paradox). The interventions are not intended to 'cure' the jealousy; indeed, we would not label it as something which needs to be cured. Rather, our aim is to see the emphasis changed so that jealousy becomes one more legitimate way for the couple to communicate with each other. To put the same point another way, we would feel that for such a couple to give up talking about the alleged infidelity would be to ask them to be untrue to the nature of their relationship. Some degree of jealousy is, in our view, a legitimate aspect of most relationships, and it would be unnatural not to have it.

The subject of jealousy has been discussed in the present paper from the systemic and couple therapy point of view. This is not to imply that other methods of therapy are not valid or useful. In the hierarchy of alternative levels of intervention we have a category which is above the 'paradoxical' one, and this is to abandon couple therapy and refer on to other means such as individual forms of psychotherapy or medication. However, it seems that to tackle a problem such as jealousy by couple therapy can offer, in many cases, an acceptable and lasting solution to an otherwise intractable problem. As yet there are very few outcome data on the treatment of jealousy by couple therapy, but clinically it seems to be a promising approach.

\section{References}

Crowe, M. \& Ridley, J. (1986) The negotiated timetable: a new approach to marital conflicts involving male demands and female reluctance for sex. Sexual and Marital Therapy, 1, 157173.

— \& - (1990) Therapy With Couples: A Behavioural Systems Approach to Marital and Sexual Problems. Oxford: Blackwell.

de Silva, P. (1987) An unusual case of morbid jealousy treated with role reversal. Sexual and Marital Therapy, 2, 179-182.

— \& Marks, M. (1994) Jealousy as a clinical problem: practical issues of assessment and treatment. Journal of Mental Health, 3 , 195-204.

Mullen, P. E. \& Martin, J. (1994) Jealousy: a community study. British Journal of Psychiatry, 164, 35-43.

Selvini Palazzoli, M., Boscolo, L., Cecchin, G., et al (1978) Paradox and Counterparadox. New York: Jason Aronson.

Shepherd, M. (1961) Morbid jealousy: some clinical and social aspects of a psychiatric syndrome. Journal of Mental Science, 107, 687-753.

Tarrier, N., Beckett, R., Harwood, S., et al (1990) Morbid jealousy: a review and cognitive behavioural formulation. British Journal of Psychiatry, 157, 319-326.

White, G. L. \& Mullen, P. E. (1989) Jealousy: Theory, Research and Clinical Strategies. New York: Guilford.

\section{Multiple choice questions}

1 Jealous ideas:

a only occur as part of the alcoholic syndrome

$\mathrm{b}$ are always accompanied by delusions

c are quite common in a community sample

d are easy to disprove by evidence

e may still cause problems even if true and justified

2 The partner of a morbidly jealous person is:

a always faithful by definition

b sometimes a contributor to the problem

c usually more outgoing than the jealous partner

d often at risk of violence

e psychologically unaffected by the jealousy

3 The treatment of jealousy by behaviouralsystems couple therapy involves:

a jealousy timetables

b insight into the unconscious cause of the problem 
c deliberately altering the relationship

d paradoxical injunctions

e improved communication

4 In the use of a paradoxical injunction:

a the therapist has to lie to the couple

b the couple must obey the instructions

c the couple must agree with what the therapist says

$d$ it is immaterial whether the couple obey or disobey the injunction

e the important thing is that the couple understand the fact that a paradox is being used

5 In a jealousy timetable:

a the jealous partner is asked to express jealousy all the time

b the other partner is asked to express jealousy

c if the jealous ideas come up at other than the appointed time the other partner can postpone their discussion

d the jealous partner is asked to restrict the time at which jealous interrogations occur

e the jealousy discussions are time-limited

\section{MCQ answers}

1

a $F$

b $\mathbf{F}$

c $\mathbf{T}$

d $F$

e $\mathbf{T}$

2

a F

b $T$

c $T$

d $T$

e $F$

3

a $T$

b $F$

c $\mathbf{T}$

d $T$

e $\mathbf{T}$ 